\title{
AIRES LIBRES Y ESCENARIOS APANTALLADOS: LAS TRANSICIONES DIFÍCILES DEL CINETEATRO HISPANÓFONO CONTEMPORÁNEO
}

\author{
Marco CIPOLLONI \\ Università di Modena e Reggio Emilia \\ marco.cipolloni@unimore.it
}

Resumen: La representación en la pantalla de la vida teatral española y latinoamericana y la influencia de las técnicas de rodaje propias del cine en el montaje de varias producciones teatrales contemporáneas tanto en España como en América Latina han reflejado, a nivel de narración y el cuento, las luchas de libertad, democracia y derecho a la memoria que muchos países hispanófonos han conocido en las décadas finales del siglo Xx. Una y otra dimensión pueden considerarse como partes complementarias del enfoque y de la perspectiva del presente ensayo, que propone una revisión crítica de una serie significativa de casos recientes. Se pretende subrayar básicamente lo siguiente: a) unos formatos de hibridismo de lenguajes y b) unos tópicos relacionados con la escenificación de la ambigua y controvertida memoria de la violencia política y de las fases transicionales desde etapas de dictadura (como el Franquismo, el Proceso argentino, el Pinochetismo de Chile, etc.) a instituciones democráticas representativas. 
Abstract: Both the cinematic representation of the stage-life in Spanish and Latin American movies and the influence of shooting techniques in contremporary Spanish and Latin American theatrical productions have been involved into the narrative and the telling of the looking for freedom and democracy that many Spanish speaking countries experienced during the last century. Both elements can be considered as complementary parts of the double focus and perspective of this paper, actually a critical survey on a representative series of recent cases. What would we highlight? Basically: a) some patterns of language hibrydation and b) some topics about the staging techniques of the fuzzy and controversial memory of the political violence and the transition phases from dictatorship (such as Spanish Francoism, Argentinian «Proceso» and Chilean Pinochetism) to representative democracies.

Palabras clave: Cine. Teatro. Democracia. Dictadura. Violencia. Memoria. Transiciones.

Key Words: Movies. Theatre. Democracy. Dictatorship. Violence. Memory. Transitional phases.

\section{PRÓlOGO: EL CINETEATRO HISPANO, DEL EXILIO A LAS TRANSICIONES DEMOCRÁTICAS}

Entre las muchas actividades de propaganda editorial y cultural que Manuel Altolaguirre intentó llevar a cabo durante la etapa mexicana de su exilio se dio también, a finales de la década del Cuarenta del siglo pasado, la tarea de difundir de pueblo en pueblo el séptimo arte. Para traducir a práctica su compromiso con los ideales del apostolado cinematográfico y convertirse en un auténtico pionero a destiempo del celuloide, Don Manuel fundó una pequeña compañía independiente y se dedicó personalmente a una serie de andanzas con sesiones itinerantes, cuyos modelos reconocibles remitían al teatro portátil y de carpa de la Comedia del Arte y a las experiencias y al espíritu del misionerismo populista y pedagógico de la II República. La grata memoria de estas excursiones al páramo (Don Quijote no dudaría en calificarlas «salidas») y de la atmósfera heróica y microemprendedora que las matizaba como aventuras picarescas de un clericus vagans por tierras de Ultramar, constan en las páginas del diario Aire libre, cuyo título documenta el placer físico de un hombre que, llenándose los pulmones con el aire ligero de las tierras altas, consigue por fin quitarse de encima no solo la agobiante po- 
lución del $\mathrm{DeFe}$ y de la Capital Federal, sino también la ingrata memoria de la guerra perdida y de sus consecuencias, es decir, el aire pesado de España, lejano e irrespirable por causa del exilio y por culpa del atosigante régimen de pesadilla policiaca instaurado, al otro lado del charco, por un terco caudillo con botas que después de haber ganado, a sangre y fuego, su guerra caliente y Nacional, acababa de pactar sus paces de Guerra fría, internacionales y muy cristianas; negocio perfectamente redondo para garantizar raíces, duración y perspectivas al pedestal violenta y despiadadamente piadoso y calculador de su mando y de su mandato.

Los experimentos de contaminación politizada y políticamente comprometida entre teatro y cine, ensayados por Altolaguirre en dicha etapa de su vida, no se limitan a los mecanismos de estreno, sino que incluyen la escenificación metateatral de la puesta en escena y del quehacer escénico, como, por ejemplo, en el caso de un guión elaborado para denunciar los efectos del macartismo, refundiendo cinematográficamente el argumento, genial y congenial, del Retablo de las maravillas cervantino. A lo largo de las décadas siguientes, el diálogo y las relaciones (muchas veces competencistas y conflictivas) entre teatro y cine se han venido utilizando repetidamente, fuera y dentro de España, para llevar a las tablas y/o a la pantalla una agenda ecopolítica puntiaguda, centrada en la reconquista del «aire libre», considerado a la vez como derecho y como deber, como supuesto y como meta de toda labor intelectual digna. El resultado escénico y metaescénico de todo esto, cuyos hitos más significativos vamos a reseñar a continuación, ha venido conformando un repertorio de cineteatro comprometido bastante amplio y muy identificado con la necesidad, los logros, los límites y las dificultades de los procesos de transición a la democracia que, a partir de la década del setenta, se han producido en muchas partes del mundo iberófono (España, Portugal, América Latina y África descolonizada y poscolonial). Dicho proceso se ha desarrollado al hilo de un trend internacional, denominado «tercera oleada» de las democratizaciones y caracterizado por una manipulación sistemática de la(s) memoria(s) del pasado y de la(s) identidad(es) del presente. La teoría y la cronología de esta «third wave of democratization» se debe al recién fallecido Huntington, cuya escuela de comparative politics, además de acuñar la afortunada etiqueta, elaboró la metodología que la utilización de dicha etiqueta conlleva y supone. Los objetos y las secuencias, marcados a partir de la perspectiva de Huntington, son evidentemente controvertibles y cuestionables por suponer una modélica democracia demasiado formal y uniformada y sobre todo por hacer caso omiso (o casi omiso) de muchas salvedades, diferencias y especificidades entre los distintos «case 
studies» posibles. Por consiguiente, el tema de las «waves of democratization» se merecería quizás una reconsideración crítica y hasta una revisión histórica. Por razones evidentes, dicha tarea rebasa con mucho las circunstancias (es decir el enfoque, el ámbito, las prioridades, los objetivos y también la perspectiva científica) de este trabajo. Por lo tanto, nos conformamos con el simple hecho de reconocer que dicho planteamiento ha tenido en su momento un prestigio y una difusión notables y que dichas circunstancias bastan para permitirnos la individuación, a nivel de general survey, de algunas analogías, reproducidas, confirmadas y multiplicadas por las actitudes vivenciales, retrospectivas y testimoniales de algunos de los protagionistas, involucrados en una idiosincrasia histórica peculiar, de la cual tenían o se creían que podían tener una conciencia casi modélica.

\section{TRADICIÓN CINETEATRAL, DICTADURAS Y NUEVAS DEMOCRACIAS: LOS MODELOS DE LUBITSCH, RENOIR, CHAPLIN, ANGHELOPULOS, MANKIEWICZ Y... BARICCO}

Desde un punto de vista científico y académico, las relaciones entre teatro y cine pueden enfocarse y apreciarse desde tres puntos de vista principales:

1. El texto teatral como argumento de cine (es decir, las puestas en escena/traducciones intersemióticas de dicho texto destinadas no a las tablas sino a la pantalla).

2. Los actores, los autores y la gente del teatro (con su visión del cine) como mundo representado y relatado por el cine (y, con menor frecuencia, lo contrario, es decir, los actores, guionistas y gente del cine representados en las escenas del teatro).

3. Las relaciones entre lenguaje teatral y cinematográfico y los recursos del uno y del otro.

Las perspectivas más frecuentadas semióticamente son evidentemente la primera y la tercera. Y sin embargo el presente estudio hace caso omiso de la primera (por ser la más evidente y la más estudiada), intentando situar su radio de acción entre la segunda y la tercera.

El marco histórico, como ya se ha dicho, lo definen las democracias de la llamada tercera oleada, con sus memorias (y desmemorias) del tiempo de las dictaduras y de los procesos transicionales correspondientes. De la 
(des)memoria aludida, la conflictiva relación entre teatro y cine («enemigos íntimos» dirían Sabina y Fito) ha sido a la vez vehículo y producto, conforme a una serie significativa de patrones sucesivos. Mientras que los faranduleros, por el simple hecho de moverse con excursiones e incursiones, cruzando a menudo el espacio social y sus fronteras, han tenido desde siempre una relación problemática, difícil y conflictiva con el poder y en especial con los poderes fuertes y sus estructuras de control y propaganda, la gente del cine, inestable plantilla de un producto a la vez industrial y técnico con textos manipulables y con estructuras productivas reconcentradas (inversiones cuantiosas y grandes Estudios), ha tenido con el mundo y la retórica de «los que mandan» una relación mucho más orgánica y de mayor sumisión (tanto del lado de la censura como del de la propaganda).

Por esta razón (que podríamos denominar «envidia/nostalgia estructural del "aire libre"»), por lo menos en una primera época, la representación cinematográfica del teatro y de la perspectiva peculiar y picaresca de su gente se ha armado al margen del mainstream de las grandes producciones, mezclando road movie y cine de autor y privilegiando los enfrentamientos y choques de las compañías itinerantes con los mundos/mandos del poder, de la guerra y de las dictaduras.

A nivel internacional el patrón más logrado (y más reconociblemente clásico) de la idiosincrasia peculiar que nos interesa suele identificarse con la película brillante To Be or Not to Be/Ser o no Ser, rodada en 1942, en EE UU, por el gran director judío alemán Ernst Lubitsch (nacido en Berlín en 1892). Otro caso al mismo tiempo representativo y singular es obviamente La carrosse d'or (1952), de Jean Renoir (nacido en París en 1894), adaptación de la novela de Thornton Wilder, The Bridge of San Luis Rey (1927), alegoría político-moral sobre la vida peruana del despotismo ilustrado y del Siglo de las Luces, metaescénicamente refundida por Renoir con efectos de teatro en el teatro y referencias al mundo de las giras y de la Comedia del Arte. El conflicto entre las espectaculares dimensiones de la carroza de oro (que representa el poder y su mundo dorado y de lujo) y las de una calzada andina que no da para tanto resume perfectamente el punto, es decir, la tensión estructural y estructurante entre el uso teatral del cartón piedra como marco de una ficción compartida y reconocible y el abuso político del mismo cartón piedra como ilusión, trampa y «engaño a los ojos».

Dichos modelos (integrados con los toques introducidos por el patetismo conmovedor de Charlie Chaplin, nacido en 1889 y autor de dos películas, fundamentales y fundacionales para nuestro argumento, como The Great 
Dictator (1940), para Lubitsch, y Limelight (1952), para Renoir, tienen un evidente y merecido prestigio y sus adaptaciones a los mapas de la tercera oleada producen varios ejemplos de «aemulatio» y refundición-homenaje. El más conocido y reconocido es sin duda la película griega El viaje de los comediantes (1975), quizás la obra maestra del director Theo Anghelopulos (nacido en Atenas en 1935). Los dos casos españoles que mejor refunden el esquema de Lubitsch y Renoir retocado por Anghelopulos son El viaje a ninguna parte (1986), de Fernando Fernán-Gómez (nacido en 1921) y iAy Carmela! (1990), de Carlos Saura (nacido en 1932), adaptación de una pieza teatral de Sanchis Sinisterra (nacido en 1940).

En todos los casos mencionados (y en otros, de películas seriales y de coproducción, como por ejemplo el tortilla-oeste ¿Qué nos importa la revolución?, rodado por Sergio Corbucci, en 1972, con Vittorio Gassman interpretando el papel de un comediante italiano involucrado en las actividades revolucionarias mexicanas de su compatriota Peppino Garibaldi, descendiente del héroe de los dos mundos), el tema se aborda de manera bastante directa, es decir, contando las paradójicas dificultades que unos tiempos difíciles, caracterizados por excesos de poder, producen en la vida andariega y precaria de unos farsantes de poca monta, mucho más serios y dignos que el gran mundo, a la vez trágico y grotesco, que los rodea. A esta misma corriente pueden sumarse también producciones algo más recientes, como La niña de tus ojos (1998), de Fernando Truba (nacido en 1955), un homenaje, casi un remake en salsa metacinematográfica y a la española de la película de Lubitsch, evocada en la misma época también por Roberto Benigni (nacido en 1952), con su chapliniano La vida es bella (1997), y por Radu Mihaileanu (nacido en 1958), con su Train de vie, 1998 (la película de Lubitsch ya había sido retomada de forma a la vez declarada y descarada por Mel Brooks, nacido en 1926 y autor en 1983 de su versión de To Be or Not to Be).

En paralelo con este formato, tragicómico, realista y suprarrealista, se ha conformado y ha tenido vigencia otro, mucho más barroco y melodramático, centrado en el tema muy teatral de la repetición, de la muerte y de la relación conflictiva entre realidad y ficción. Este formato, más que al cine de autor, se vincula a la estética exagerada del dramatismo cinematográfico de la Edad de Oro de Hollywood, es decir, al canon alrededor del cual han pivotado muchas grandes producciones, musicales y no, del cine norteamericano de las décadas de los cuarenta y los cincuenta. Dejando de lado el cine estrictamente musical (nos limitamos a subrayar que, apoyándose en el repertorio de la ópera ligera, cuenta con una inagotable galería de príncipes ridículos, verdaderos señoritos de horca y cuchillo de pequeñísimos estados de los Bal- 
canes), cabe señalar el cine de Vidor, especializado en la reconstrucción de la trastienda cruel del mundo del teatro de Broadway, y sobre todo el afortunado subgénero de las chicas de provincias que logran/no logran triunfar en la capital (sobra decir que dicho esquema, muy de Cenicienta, establece, mediante sus «príncipes azules», enlaces directos con la cumbre misma del poder: para comprobarlo es suficiente aludir a la biografía de Marilyn o a la memoria compartida de dos espectáculos de gran éxito de Andrew LloydWebber y Tim Rice, como El fantasma de la ópera y sobre todo Evita, posteriormente cinematografiado por Alan Parker con la interpretación de Madonna). Y sin embargo el caso más significativo para el cine de lengua española es sin duda el de All About Eve (1950), de Joseph Mankiewicz (nacido en 1909), retomado de manera genial y congenial por Pedro Almodóvar, nacido cuarenta años más tarde (y por lo tanto coetáneo de la gran película), en Todo sobre mi madre (1999).

La relectura posmodernista que Almodóvar ofrece de la obra de Mankiewicz modifica profundamente el esquema lineal que gobierna el género, introduciendo elementos de un esquema circular, que, además de suponer una secuencia significativa de gestos y generaciones que se repiten (también fuera de las escenas), admite y documenta la irrupción de un planteamiento identitario realmente novedoso, que transforma las tablas del escenario no en una cárcel o en una trampa de relojería, sino en un lugar de autoafirmación privilegiado, lo más auténticamente identitario que cualquier otro (todo esto resulta muy evidente, pero, en beneficio de los torpes y distraídos, Almodóvar lo hace constar de forma totalmente explícita y con acentos de genial parodia didascálica, mediante el conocido monólogo de Agrado, interpretado por Antonia San Juan). Los diecisiete años de vida del joven Esteban, hijo de una pareja de refugiados argentinos, formada por Manuela (Cecilia Roth) y por el travesti Lola, conectan el presente narrativo de los acontecimientos contados la película (es decir, la España de la democracia) directamente con la etapa crucial de la tercera oleada, es decir con la segunda mitad de la década del setenta del siglo pasado, cuando la llegada, en la España de la transición, de cuantos intentaban escaparse de la violencia brutal y de la represión salvaje desencadenada por la Junta Militar del Proceso argentino. El hecho de que la máquina del tiempo suponga un desplazamiento de Madrid a Barcelona y que conecte con el mundo del teatro, gracias a la compañía de Huma Rojo (Marisa Paredes) y a la pieza de Tennessee Williams (nacido en 1911), A Streetcar Named Desire, de 1948 (decisiva para el tránsito del teatro al cine de dos personajes de la talla artística de Elia Kazan y Marlon Brando), permite que los personajes tomen conciencia de la dialéctica entre 
historia (asumir y resumir el pasado y la línea paterna del repertorio y de la autoría) y deseo (proyectarse hacia el futuro y la línea materna de la interpretación y de la actoría).

La idea sigue siendo la de sobrevivir a las desapariciones, pero la ruptura introducida por Almodóvar en la línea Lubitsch-Renoir-Chaplin, hasta la fecha dominante, hace patente la conexión entre la transición española y las de América Latina y sobre todo hace del temario del teatro y de la homosexualidad (masculina y femenina) una metáfora vivencial del espacio transicional. A medio camino entre una línea y otra, como posible punto de contacto entre las propuestas de Saura y Fernán-Gómez y la de Almodóvar, puede señalarse el caso de dos películas como Las cosas del querer (1989), y Las cosas del querer 2 (1995), ambas de Jaime Chávarri (nacido en 1943). En estas dos películas el mecanismo narrativo es el de Lubitsch y Renoir (la gira por tierras de Ultramar como escapatoria y salida de emergencia), pero el escenario transatlántico, el tema homosexual y la estética sobrecargada y cursi se acercan notablemente a la manera melodramática de Mankiewicz y al mundo transatlántico en que se mueven los protagonistas de Almodóvar.

En la primera década del tercer milenio a todas estas líneas se suman las de otros experimentos, algo menos conocidos, pero más abiertamente interesados en confundir lingüísticamente las pistas del teatro y del cine, insistiendo en la idea de mezclar lenguajes y recursos para hablar de transiciones y violencia política en España y América Latina:

- En 1995, Roman Polanski (nacido en 1933), adapta para la pantalla Death and the Maiden. Su fuente es la pieza teatral La muerte y la doncella, del chileno Ariel Dorfman (nacido en 1942). Polanski, que piensa en películas de mucha tensión como Cape Fear (1962), del director de Casablanca J. Lee Thompson (con remake, 1991, de Martin Scorsese, nacido en 1942), como su propio Cul de sac (1966), como Straw Dogs (1971), de Sam Peckinpah (nacido en 1925), y como Il portiere di notte (1974), de Liliana Cavani (nacida en 1933), y que, obviamente, no puede ni quiere prescindir de la tragedia de Bel Air, añade mucho de su cosecha a la pieza, exasperando la atmósfera de thriller claustrofóbico, pero salva la estructura teatral del trabajo de Dorfman, complicándola con otras claves simbólicas recurrentes (es decir, añadiendo el agua a las notas de Der Tod und Das Madchen, de Schubert).

- En 1998, primera época de la llamada «retomada» (el nuevo auge del cine brasileño), Beto Brandt (nacido en 1964) filma Ação entre ami- 
gos, una película de estructura muy teatral sobre la venganza, organizada por un grupo de cuatro amigos en contra de su antiguo torturador, reconocido y perseguido, con dudas y sin piedad, muchos años después. La película comparte fuentes cinematográficas con la de Polanski, pero también conecta con películas de estética y psicología más convencionales, como The Marathon Man (1976), de John Schlesinger (nacido en 1926), y The Boys from Brazil (1978), de Franklin Schaffner (nacido en 1920).

- El caso del Fausto 5.0, película de 2001, de Álex Ollé (n. 1960), Isidro Ortiz (n. 1963) y Carlos Padrissa (n. 1959), es más complejo, puesto que el vínculo con el teatro del poder es doble. Por un lado, procede de la propia figura de Faust y por otro, tiene que ver con el hecho de ser los autores del proyecto unos miembros destacados de la muy conocida compañía teatral catalana «La Fura dels Baus». La metáfora del poder sobre cuerpos y almas se filtra a través de la ciencia de la salud y de la enfermedad y la lógica infernal del dominio se identifica de hecho con la de un errado diagnóstico y de un cáncer que, después de tragarse las entrañas y la vida, sueñan con tragarse la conciencia, controlando, manipulando y dosificando la información. Imagen y narración se desequilibran para adaptarse a las exigencias de un video-experimentalismo de muy reconocible abolengo escénico. El nuevo doctor Fausto, interpretado por el actor argentino Miguel Ángel Solá, es amenazado y seducido por un demonio que ha sido paciente suyo, es decir, que ha sido de alguna manera (pro)creado por él.

- Otro caso muy interesante es, en 2002, el de la película Noviembre, de Achero Mañas (nacido en 1970), hijo de la actriz Paloma Lorena y del dramaturgo Alfredo Mañas. La película, mezclando ficción y entrevistas documentales, ficcionaliza las actividades de una compañía independiente del living theatre de la época de la transición, denominada «El piojo picón» y especializada en armar provocaciones callejeras. Este núcleo histórico, documentado por los testimonios de los antiguos miembros de la agrupación (entre los cuales figura la madre del director), funciona como base a partir de la cual se elabora una línea paralela de acción, dedicada a las actuaciones de otra compañía, inventada y denominada «Noviembre», que, veinte años después, retoma el espíritu anticomercial y las provocaciones del tiempo de la transición, volviendo a reponerlas por las calles del Madrid pepero de la etapa anterior al atentado de Atocha. El resultado es una especie de documental en vivo, armado al hilo de una 
comparación entre el tiempo de la (primera) transición y el de la que el españolismo de José María Aznar insistía en llamar «segunda transición». En palabras del propio Achero Mañas'1:

Es cierto que este teatro utópico y libre se dio en circunstancias especiales y en una época determinada, pero... ¿Qué pasaría ahora si surgiera un grupo teatral como los que aparecieron entonces? ¿Podría darse en la década de los noventa un grupo con el mismo espíritu, o parecido? ¿De qué forma surgiría? ¿Tendría algo por lo que luchar? ¿Cuál sería su sentido ahora? ¿Cómo reaccionaría el público? ¿Qué pasaría si el teatro volviera a la calle? ¿Aportaría algo? Y lo que es más importante, ¿podría sobrevivir? ¿Qué pensarían sus integrantes pasados cuarenta años? ¿Pensarían lo mismo que piensan los actores de los grupos de entonces en este momento? Noviembre ha sido un intento de dar respuesta a esas preguntas.

- Otro espectáculo muy original y significativo es la pieza Angora Matta: Tangópera-Thriller/Fatal Acts of North South Translation, con texto (y variaciones críticas) de Marta Helena Savigliano y música de Ramón Pelinsky (nacido en 1932), de 2003, un ensayo teatral para one-woman-band, lleno de referencias al cine negro y a sus tópicos. La protagonista, Angora Matta, es una refugiada argentina afincada en Los Ángeles, desde finales de la década del setenta. Su papel resulta ser, a todas luces, el de una prototípica mujer fatal, tanto desde el punto de vista del repertorio icónico (ademanes desganados y despiadados, actitud cínica y calculadora, zapatos de tacón, trajes con escote de night club, cigarillos, burdo maquillaje, pausas estudiadas, etc.), como desde un punto de vista más estrictamente profesional, puesto que trabaja como asesina a sueldo y acepta un contrato para liquidar al (por supuesto) corrupto Presidente de su país de origen. Para cumplir con sus obligaciones de mujer killer se repatría, volviendo a pisar el suelo de Buenos Aires y, sobre todo, el de sus boliches y milongas. La comparación entre las dos épocas de su vida y los ecos (no tan lejanos) de la barbarie política y del hundimiento económico que han golpeado a las sociedades del Cono Sur se suman in crescendo hasta el desenlace, permitiendo a la autoría múltiple de Savigliano (que es profesora de Universidad) unos ejercicios complementarios de corte paródico, vinculados al tema de la

${ }^{1}$ Sacadas del pressbook de la película y reproducidas en varias páginas de la web, entre ellas: http://archivodigital. cervantes.es/documentacion/Noviembre_sinopsis\%20y\%20notas.pdf). 
globalización y a los formatos del discurso académico. Otro núcleo discursivo tiene que ver con el tango y con los nexos de sus tópicos con los del teatro y del cine. El tango viene a ser la lengua que hace posible el diálogo entre los dos mundos, la clave de todo discurso alrededor del pasado y de la memoria.

- La película documental chilena Actores secundarios, de Pachi Bustos y Jorge Leiva (2004), dedicada a la memoria del movimiento estudiantil antipinochetista chileno de los años ochenta, mezcla los testimonios de los protagonistas entrevistados con imágenes y fotos de found footage $\mathrm{y}$, teatralmente, con la puesta en escena contemporánea, mediante actores jóvenes, de las actividades, iniciativas y manifestaciones de protesta organizadas en la época por la AES (Asociación de Estudiantes Secundarios: deletreando el acrónimo se entiende también el juego de palabras del título). La realización de dichas tomas en el Liceo de Aplicación, en donde las primeras protestas se habían desarrollado, supuso problemas y malentendidos con las autoridades democráticas, en exceso preocupadas de curarse en salud de las consecuencias de la puesta en escena de una memoria de crítica y de participación. Otros pasajes notables documentan la vuelta de los antiguos estudiantes, hoy hombres y mujeres de mediana edad, a los edificios de su encarcelamiento, interrogatorio y tortura.

- Una de las piezas de mayor interés, también por su original manera de mezclar teatro y cine, es Sin Sangre, espectáculo de Juan Carlos Zagal y de la compañía Teatro-Cinema, integrada por los antiguos miembros de La Troppa, una de las iniciativas teatrales más significativas y de mayor proyección internacional de la escena teatral chilena reciente. El espectáculo escenifica la novela corta Senza sangue (2002), de Alessandro Baricco, en el marco de un escenario casi totalmente conformado por la superposición de múltiples efectos de proyección. Objetos, fondos y figuras de ambiente se mueven alrededor de los personajes, logrando en la escena efectos muy parecidos a los del lenguaje cinematográfico (close-up sobre detalles, flashbacks, montajes analógicos). Todo se centra, como bien dice uno de los protagonistas, en una «absurda fidelidad al horror». Al comienzo vemos el largo viaje (muy de road movie) de un commando, integrado por el intelectual Salinas, el violento Gurre y el «muchacho» (es decir, el hijo de una víctima), hacia la venganza. El victimario perseguido, que se ha refugiado en el campo de Mato Rujo con lo que queda de su familia, es el Doctor Manuel Roca, apodado «la Hiena», 
director de un hospital de torturas físicas y psicológicas durante largos y crueles años de dictadura y guerra civil (de una república latinamericana cuyo mombre no se detalla). Los efectos logrados mediante proyecciones permiten evidenciar claves simbólicas, armar escenas dobles y cambios de escena y de luces y, sobre todo, logran ubicar a los personajes en un espacio fronterizo, reconociblemente colonizado por la memoria del cine, un teatro en el cual un personaje puede decirle a otro cosas como: «me parece que has visto demasiadas películas», «Ud. se parece a un héroe de película antigua», etc. La pieza tiene dos partes. En la primera, de más acción, se cumple la venganza: el terceto llega al caserío en que se ha escondido el doctor; incursiona, mata al torturador y al hijo varón que intenta rescartarle y, para destruir toda evidencia, transforma en un cadalso la vieja y destartalada mansión; en la segunda parte, muchos años después, vuelven a encontrarse, conversan y se cuentan sus vidas, reales e imaginadas, con muchos flash-backs y cruces de caminos, los únicos protagonistas que siguen con vida, es decir la hija menor del doctor, escapada de la quema y transformada por la vida en una mujer fatal de retorcidos sesos y muchos nombres (Nina y Sole, es decir, niña y soledad, los más significativos) y el antiguo «muchacho» (tan agotado y sin nombre que su verdadero nombre, bastante elegido, Pedro Cantos, solo se revela al final). Los dos, conscientes de ser fantasmas de otra época, gastados por el tiempo, más llenos de cansancio que de miedo, acaban haciendo las paces y salen de la larga pesadilla de sus respectivos mundos posibles haciendo el amor en la cama de un hotel barato, totalmente digno de las pinceladas de Hopper. La complicada red de sus vidas mutuamente contadas remite al repertorio de la novela (una novela cursi, de melodrama cabaretero, con acosos y abusos de viejos y de aristócratas, la de ella; una novela negra, llena de conspiraciones y de resignaciones, la de él). Doña Sole es una Angora Matta sin tango, una mujer fatal decepcionada mucho antes de tener romance; Pedro es un héroe de hard boiled previamente venido a menos, sin agencia de investigaciones y que se gana la vida vendiendo boletos de la lotería, convencido de que «un mundo mejor, habría que pelearlo», pero también consciente de que las fuerzas ya no le alcanzan, ni daban para tanto.

- La andanza más reciente (hasta la fecha) de nuestro repertorio cineteatral es la película española Días de cine (2007), de David Serrano (nacido en 1975, el año de la muerte del General Franco). La historia, 
una comedia amarga con resabios de farsa trágica, cuenta el fracaso de una tentativa de pasar del teatro al cine en la España de 1977, es decir, en los años abiertos y llenos de ilusiones de la primera transición. Un joven autor de teatro con muchas buenas ideas y un merecido prestigio de antifranquista quiere rodar un drama social para compartir sus ideales con una audiencia más amplia. Su proyecto y sus esperanzas se cruzan con los afanes de reciclaje de una folclórica y de su empresario, que buscan un camino para seguir haciendo, con patentes de cultura y democracia, lo que han hecho durante toda su vida, artística y no: adaptarse a las exigencias y caprichos del poder del momento, sea el que sea. La relación tensa entre el joven director y su estrella de mediana edad y de bastantes agotados talentos tiene todos los supuestos, pero no la liviandad y el optimismo de The Band Wagon (1953), de Vincent Minnelli, con Fred Astaire en el papel de vieja gloria de la escena y Cyd Charisse, que sueña con soluciones novedosas. El resultado sigue siendo un muy rotundo fiasco, pero es también una intencionada y despiadada parodia de las malogradas relaciones entre intelectuales y pueblo, cultura y experiencia, compromiso y compromisos. Los sueños y los ideales se pierden y manchan sin remedio para poder convertirse en realidad.

Un abanico tan amplio como el que se acaba de reseñar, con artistas nacidos entre finales del XIX y 1975, y con tanta variedad de soluciones, técnicas y narrativas, documenta con creces la insatisfacción transgeneracional que todo proceso transicional conlleva. Cualquiera que sea la solución experimentada (perdonismo, impunidad, olvido, rendición de cuentas, venganza, justicia, leyes de punto final, etc.), la memoria del pasado y las cicatrices de la violencia siguen pesando mucho y determinando un fondo de amargura, amplificado por la circunstancia ingrata del envejecimiento, tanto del cuerpo como de los ideales. La tónica y la tópica del asunto acaban situándose muy al hilo del Sunset Boulevard (1950), de Billy Wilder (nacido en 1906). Tanto los hombres de pluma desganados y precozmente envejecidos como las viejas estrellas que se niegan a despedirse de la escena acaban siendo máscaras crueles de un destino burlador, a la vez patético y trágico. El cine y el teatro de las transiciones, con sus relaciones, conforman un doble de la aludida pareja prototípica. Como Joe (William Holden), el cine es indudablemente más joven de edad, pero es también más cínico y mucho más quemado. El teatro, en cambio, se parece bastante a Norma Desmond (Gloria Swanson): se cae a pedazos y se repite mucho, pero sueña con renovarse y con tener otra oportunidad. El desenlace de su relación no hace otra cosa 
sino aclarar a cada cual el ineludible punto final de la línea de su mano: la muerte en un caso («el cine es la muerte actuando», decía Cocteau); la locura en el otro.

Si lo pensamos bien, tanto hundimiento se acaba en y con el cuerpo y el alma de los personajes femeninos: si la regresiva Sole de Baricco y Zagal llega un pelín más lejos que la Angora Matta de Savigliano y que la Paulina Escobar de Dorfman y Polanski, la compasiva y superviviente Manuela de Almodóvar (Cecilia Roth) llega mucho más allá que la Carmela víctima sacrifical (Carmen Maura) de Saura y Sanchis Sinisterra. La vida y las generaciones (las madres, las abuelas y los H.I.J.O.S. del Cono Sur, refundidos por el acento sudaca de «la madre» Manuela) pueden más que las claves simbólicas de la muerte y la memoria (la República y su bandera, papel y envoltorio de Carmen y de su muerte).

La representación del teatro (y de sus problemáticas relaciones con el cine) en la pantalla democrática nos restituye una imagen antirretórica y bastante fiel de las transiciones difíciles que han conformado la «tercera oleada», unas transiciones tanto más logradas y exitosas cuanto más ajenas al monumentalismo y abiertas al movimiento y al rescate de la memoria viva de «las cosas del querer», es decir, como bien saben el bolero y el tango, del sufrimiento y del fracaso. Como en toda gira que se precie, el sabor, el recuerdo y el temor del fiasco tienen que formar parte del corazón, del alma y de la conciencia del aplauso. 